\title{
Draft genome sequence of Francisella tularensis subsp. holarctica BD11-00177
}

\author{
Jordy P. M. Coolen', Andreas Sjödin², Boulos Maraha ${ }^{3}$, Gerard F. Hajer ${ }^{4}$, Mats Forsman², \\ Ellen Verspui ${ }^{5}$, Hendrina M.E. Frenay ${ }^{3}$, Daan W. Notermans ${ }^{6}$, Maaike C. de Vries ${ }^{6}$, Frans \\ A.G. Reubsaet ${ }^{6}$, Armand Paauw ${ }^{1}$, Guus Roeselers ${ }^{1}$. \\ ${ }^{1}$ TNO, The Netherlands \\ ${ }^{2}$ Division for CBRN Defence and Security, FOI - Swedish Defence Research Agency, Umeå, \\ Sweden \\ ${ }^{3}$ Department of Medical Microbiology, Beatrix Hospital, Gorinchem and Albert Schweitzer \\ Hospital, Dordrecht, The Netherlands. \\ ${ }^{4}$ Department of Surgery, Beatrix Hospital, Gorinchem, The Netherlands \\ ${ }^{5}$ Public Health Service Zuid Holland Zuid, Dordrecht, The Netherlands \\ ${ }^{6}$ Diagnostic Laboratory for Infectious Diseases and Perinatal Screening (LIS), Center for In- \\ fectious Disease Control, National Institute of Public Health and the Environment (RIVM), \\ Bilthoven, The Netherlands
}

Correspondence: Guus Roeselers (guus.roeselers@tno.nl)

Keywords: tularaemia; biodefence; zoonotic infection; phylogeography; Netherlands

Francisella tularensis is a facultative intracellular bacterium in the class
Gammaproteobacteria. This strain is of interest because it is the etiologic agent of tularemia
and a highly virulent category A biothreat agent. Here we describe the draft genome se-
quence and annotation of Francisella tularensis subsp. holarctica BD11-00177, isolated from
the first case of indigenous tularemia detected in The Netherlands since 1953. Whole ge-
nome DNA sequence analysis assigned this isolate to the genomic group B.FTNF002-00,
which previously has been exclusively reported from Spain, France, Italy, Switzerland and
Germany. Automatic annotation of the 1,813,372 bp draft genome revealed 2,103 protein-
coding and 46 RNA genes.

Abbreviations: CDC- United States Centers for Disease Control and Prevention, TNO- Dutch Organization for Applied Scientific Research, FOI- Swedish Defence Research Agency

\section{Introduction}

Francisella tularensis is a Gram negative, nonmotile, non-spore forming, facultative intracellular bacterium appearing as short rods or coccoid forms [1]. F. tularensis is the etiologic agent of tularemia, a zoonotic infection also known as rabbit fever and deer-fly fever. Transmission to humans has been reported by direct contact with infected animals, arthropod bites, inhalation of contaminated dust or ingestion of contaminated food or water. This pathogen is highly infectious as it can cause infection upon inhalation of as few as 10 cells. This extremely low infectious dose makes transmission via aerosols easy, and previous attempts to weaponize this microorganism have led to its recognition as a category A biothreat agent (CDC classification) [2,3]. F. tularensis contains three subspecies that are infectious to humans; the highly virulent Francisella tularensis subsp. tularensis, which often causes a lethal multisystemic disease with a fatality rate of up to $30 \%$, the less virulent Francisella tularensis subsp. holartica and Francisella tularensis subsp. mediasiatica, which both seldom cause infectious in humans. Here we present a summary classification together with the description of the draft genome sequence and annotation of Francisella tularensis subsp. holarctica BD11-00177, that was isolated from a vesicle on the forehead of a 72year-old male living in The Netherlands. As the patient had not been abroad for years, this was the first documented case of indigenous tularemia in The Netherlands since 1953. 


\section{Classification and features}

Francisella is the only genus within the family Francisellaceae and is a member of the order Thiotrichales and the class Gammaproteobacteria [4] [Table 1]. Besides F. tularensis, the genus Francisella includes the species Francisella halioticida, Francisella hispaniensis, Francisella noatunensis, Francisella novicida, Francisella philomiragia, Francisella cantonensis and the mis- classified Wolbachia persica [4,17, Figure 1]. Only rare human infections with $F$. hispaniensis and $F$. novicida, and $F$. philomiragia are described, often caused after nearly drowning $[18,19]$. F. tularensis is capable of infecting hundreds of different vertebrate and invertebrate hosts [20]. The most widely distributed subspecies is $F$. tularensis subsp. holarctica, which is found throughout much of the Northern Hemisphere and is the only subspecies naturally occurring in Europe [21].

Table 1. Classification and general features

\begin{tabular}{|c|c|c|c|}
\hline MIGS ID & +2 & Term & Evidence code $^{a}$ \\
\hline & \multirow{9}{*}{ Current classification } & Domain Bacteria & TAS [5] \\
\hline & & Phylum Proteobacteria & TAS [6] \\
\hline & & Class Gammaproteobacteria & TAS $[7,8]$ \\
\hline & & Order Thiotrichales & TAS $[7,9]$ \\
\hline & & Family Francisellaceae & TAS [7-10] \\
\hline & & Genus Francisella & TAS [11-14] \\
\hline & & Species Francisella tularensis & TAS $[11,12]$ \\
\hline & & Subspecies Francisella tularensis holarctica & TAS $[15,16]$ \\
\hline & & Strain BD11-00177 & NAS \\
\hline & Gram stain & negative & TAS [1]. \\
\hline & Cell shape & short rods or coccoid forms & TAS [1]. \\
\hline & Motility & No & TAS [1]. \\
\hline & Sporulation & No & TAS [1]. \\
\hline & Temperature range & Mesophilic & TAS [1]. \\
\hline & Optimum temperature & $37-1$ & IDA \\
\hline & Carbon source & Carbohydrates & TAS [1]. \\
\hline & Energy source & Chemoorganotrophic & TAS [1]. \\
\hline & Terminal electron receptor & Facultative anaerobe & TAS [1]. \\
\hline MIGS-6 & Habitat & Host & TAS [1]. \\
\hline \multirow[t]{5}{*}{ MIGS-15 } & Biotic relationship & Obligate host-dependent & TAS [1]. \\
\hline & Host name & Homo sapiens & TAS [1]. \\
\hline & Host taxon ID & 9606 & TAS [1]. \\
\hline & Host gender & Male & NAS \\
\hline & Pathogenicity & Pathogen & \\
\hline MIGS-14 & Biosafety Level & 3 & TAS [2]. \\
\hline MIGS-4 & Geographic location & The Netherlands & IDA \\
\hline MIGS-5 & Sample collection time & October 2011 & IDA \\
\hline MIGS-4.1 & Latitude & unknown & \\
\hline MIGS-4.2 & Longitude & unknown & \\
\hline MIGS-4.3 & Depth & unknown & \\
\hline \multirow[t]{2}{*}{ MIGS-4.4 } & Altitude & unknown & \\
\hline & Isolate site Human host & & IDA \\
\hline MIGS-4.5 & Isolation source & vesicle on the forehead & IDA \\
\hline
\end{tabular}

aEvidence codes - IDA: Inferred from Direct Assay; TAS: Traceable Author Statement [i.e., a direct report exists in the literature); NAS: Non-traceable Author Statement [i.e., not directly observed for the living, isolated sample, but based on a generally accepted property for the species, or anecdotal evidence). These evidence codes are from the Gene Ontology project. 


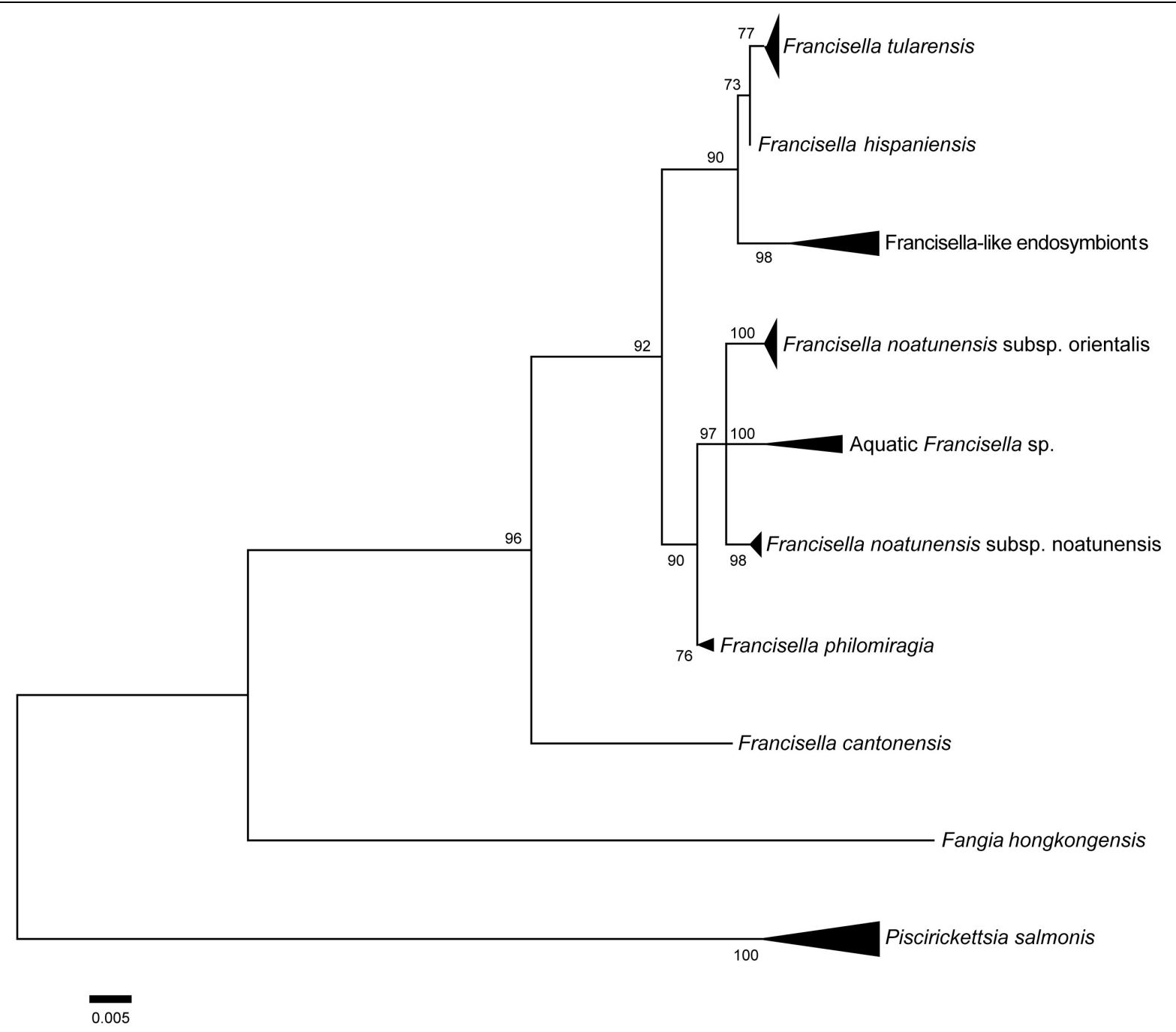

Figure 1. Maximum likelihood tree illustrating the phylogenetic relationships among several members of the genus Francisella and members of the order Thiotrichales based on full-length 16S rRNA gene sequences.

\section{Genome sequencing information}

\section{Genome project history}

Strain BD11-00177 was sequenced because of its relevance to biodefense. The draft genome sequence was finished in August 2012. The GenBank accession number for the project is 177784 . The genome project is listed in the Genome OnLine Database (GOLD) [22] as project Gi21611. Sequencing was carried out at the Dutch Organization for Applied Scientific Research (TNO) and the Swedish Defense Research Agency (FOI). Initial automatic annotation was performed using the DOE-JGI Microbial Annotation Pipeline (DOE-JGI MAP). Table 2 shows the project information and its association with MIGS 2.0 compliance.

\section{Growth conditions and DNA isolation}

For DNA preparation, strain BD11-00177 was grown on $5 \%$ sheep blood agar plates for $72 \mathrm{~h}$ at $35^{\circ} \mathrm{C}$ in the presence of $5 \% \mathrm{CO}_{2}$. DNA was extracted using the Qiamp DNA Micro Kit according manufacturers guidelines (Qiagen, Westburg b.v., Leusden, The Netherlands).

\section{Genome sequencing and assembly}

Sequencing was performed by the Microbiology and Systems Biology group at TNO and the Division for CBRN Defence and Security at FOI using 454 Roche GS Junior and the Illumina MiSeq platforms. The initial draft assembly yielded 95 large $(>1,000 \mathrm{bp})$ and 86 small $(<1,000 \mathrm{bp})$, nonredundant contigs of $1,813,372$ bp by combing 75,245 Roche/454 reads at $23 \times$ coverage and $8,289,332$ Illumina reads at $690 \times$ coverage by hybrid assembly through the Ray Assembler V2.1 [24]. 


\begin{tabular}{lll}
\multicolumn{2}{l}{ Table 2. Project information } & \\
\hline MIGS ID & Property & Term \\
\hline MIGS-31 & Finishing quality & Standard Draft \\
MIGS-29 & Sequencing platforms & Illumina MiSeq, 454 Roche GS Junior \\
MIGS-31.2 & Fold coverage & $713 \times$ \\
MIGS-30 & Assemblers & Ray Assembler V2.1 \\
MIGS-32 & Gene calling method & Prodigal [23] \\
& GOLD ID & Gi21611 \\
& IMG Taxon ID & 1244086 \\
& NCBI PROJECT ID & 177784 \\
MIGS-38 & Project relevance & Medical, biodefence \\
\hline
\end{tabular}

\section{Genome annotation}

Open Reading Frames (ORFs) were predicted using the Prodigal gene prediction algorithm [23] as part of the DOE-JGI Microbial Annotation Pipeline (DOE-JGI MAP) using default parameters, followed by a round of manual curation. CRISPR elements were predicted using CRT and PILERCR [25]. Predictions from both methods were concatenated. Identification of tRNAs was performed using tRNAScan. Ribosomal RNA genes (5S, 16S, 23S) are predicted using the program RNAmmer [26]. With the exception of tRNA and rRNA, all models from Rfam [27] are used to search the genome sequence. For faster detection, sequences are first compared to a database containing all the ncRNA genes in the Rfam database using BLAST, with a very loose cutoff. Subsequently, sequences that have hits to any genes belonging to an Rfam model are searched using the program INFERNAL [27].
Protein coding genes were compared to protein families (e.g., COGs, Pfam, KEGG) and the proteome of selected "core" genomes, which are publicly available, and the product names were assigned based on the results of these comparisons.

\section{Genome properties}

The genome was assembled into 95 large $(>1,000$ bp) contigs and includes one circular chromosome with a total size of $11,813,372 \mathrm{bp}(32.23 \%$ GC content). A total of 2,149 genes were predicted, 2,103 of which are protein-coding genes. Of the protein coding genes, 1,592 were assigned to a putative function, with the remaining being annotated as hypothetical proteins. The properties and the statistics of the genome are summarized in Tables 3 and 4.

Table 3. Nucleotide content and gene count levels of the genome

\begin{tabular}{lrr}
\hline Attribute & Value & \% $^{\text {of total }} \mathbf{~}^{\mathbf{a}}$ \\
\hline Genome Size (bp) & $1,813,372$ & $100.00 \%$ \\
DNA coding region (bp) & $1,611,603$ & $88.87 \%$ \\
DNA G+C content (bp) & 584,435 & $32.23 \%$ \\
Total genes & 2149 & $100.00 \%$ \\
RNA genes & 46 & $2.14 \%$ \\
Protein-coding genes & 2103 & $97.86 \%$ \\
Genes in paralog clusters & 1262 & $58.72 \%$ \\
Genes assigned to COGs & 1584 & $73.71 \%$ \\
Protein coding genes connected to KEGG pathways & 611 & $28.43 \%$ \\
not connected to KEGG pathways & 1492 & $69.43 \%$ \\
Genes with signal peptides & 111 & $5.17 \%$ \\
Genes with transmembrane helices & 573 & $26.66 \%$ \\
\hline
\end{tabular}

a) The total is based either on the size of the genome in base pairs or on the total number of protein coding genes in the annotated genome. 
Table 4. Number of genes associated with the 25 general COG functional categories

\begin{tabular}{crrl}
\hline Code & Value & \%age $^{\mathbf{a}}$ & Description \\
\hline J & 152 & 8.79 & Translation \\
A & 1 & 0.06 & RNA processing and modification \\
K & 65 & 3.76 & Transcription \\
L & 198 & 11.45 & Replication, recombination and repair \\
B & - & - & Chromatin structure and dynamics \\
D & 18 & 1.04 & Cell cycle control, mitosis and meiosis \\
Y & - & - & Nuclear structure \\
V & 31 & 1.79 & Defense mechanisms \\
T & 24 & 1.39 & Signal transduction mechanisms \\
M & 112 & 6.47 & Cell wall/membrane biogenesis \\
N & 19 & 1.1 & Cell motility \\
Z & 1 & 0.06 & Cytoskeleton \\
W & - & - & Extracellular structures \\
U & 44 & 2.54 & Intracellular trafficking and secretion \\
O & 66 & 3.82 & Posttranslational modification, protein turnover, chaperones \\
C & 107 & 6.18 & Energy production and conversion \\
G & 118 & 6.82 & Carbohydrate transport and metabolism \\
E & 158 & 9.13 & Amino acid transport and metabolism \\
F & 65 & 3.76 & Nucleotide transport and metabolism \\
H & 96 & 5.55 & Coenzyme transport and metabolism \\
I & 64 & 3.7 & Lipid transport and metabolism \\
P & 71 & 4.1 & Inorganic ion transport and metabolism \\
Q & 37 & 2.14 & Secondary metabolites biosynthesis, transport and catabolism \\
R & 172 & 9.94 & General function prediction only \\
S & 111 & 6.42 & Function unknown \\
- & 565 & 26.29 & Not in COGs \\
\hline
\end{tabular}

a) The total is based on the total number of protein coding genes in the annotated genome.

\section{Comparisons with other fully sequenced genomes}

Comparison of the assembled draft genome sequence of strain BD11-00177 with publicly available $F$. tularensis genome sequences revealed that it clusters in the FTNF002-00 genomic group (B.Br.FTNF002-00 and BIV.FTNF002-00) defined by the FTNF002-00 genome sequence [28-30] within the B.IV clade. The presence of the $1.59 \mathrm{~kb}$ RD23 deletion event [31] as well as the 464 bp size of the MLVA marker FtM24 [32], both typical for the FTNF002-00 genomic group, were confirmed in silico. Notably, isolates from this genomic group had previously been exclusively reported from Spain, France, Italy, Switzerland and Germany [28,31-35].

A BLAST Ring Image Generator (BRIG) analysis comparing the $F$. tularensis subsp. holarctica BD1100177 genome against the $F$. tularensis subsp. holarctica genomes of F92, LVS, and FTNF002-00 revealed that the BD11-00177 draft genome shows considerable resemblance to FTNF002-00 (Figure 2).

Evolutionary history of $F$. tularensis subspecies holarctica strain BD11-00177 was inferred using publicly available whole genome sequences.

The trees in Figure $3 \mathrm{~A}$ and B are drawn to scale, with branch lengths in the same units as those of the evolutionary distances used to infer the phylogenetic tree. The evolutionary distances were computed using the number of differences method and are in the units of the number of base differences per sequence. The overview of Francisella genus involved 52 public genome sequences using Piscirickettia salmonis as outgroup (Figure 3A). The detailed analysis involved $14 F$. tularensis subsp. holarctica genome sequences using $F$. tularensis subsp. tularensis strain SCHU S4 as outgroup (Figure 3B) [17,30,33,36-41]. All positions containing gaps and missing data were eliminated. There were a total of 1,599,589 positions in the final dataset. 


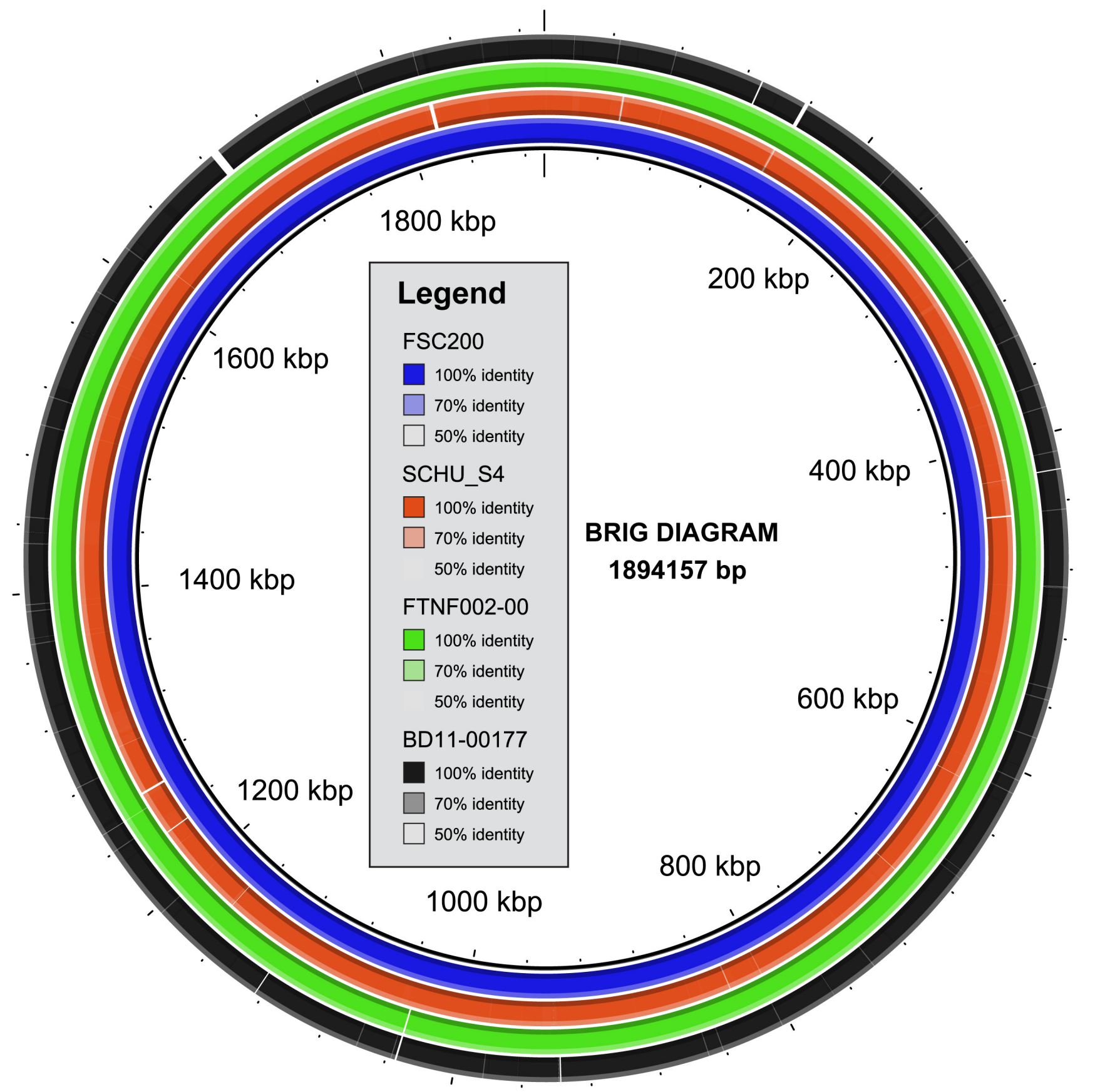

Figure 2. BRIG diagram of the $F$. tularensis subsp. holarctica BD11-00177, FTNF002-00 and SCHU S4 genomes using the $F$. tularensis subsp. holarctica FSC200 genome as a reference backbone. White regions represent absent genetic regions. 

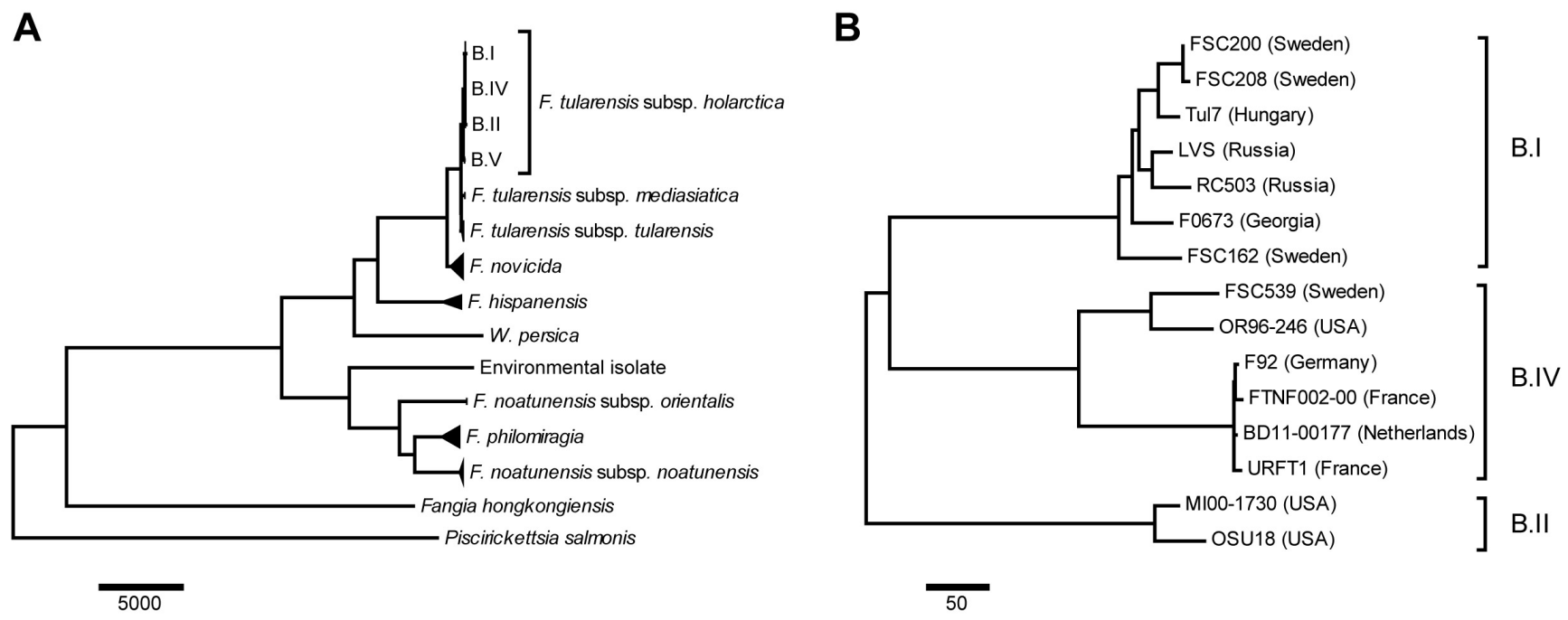

Figure 3. A) Overview of the Francisella genus phylogeny based on 52 public whole genome sequences. B) The phylogeny of $F$. tularensis subsp. holarctica strains based on whole genome sequences. The new isolate, BD1100177 belongs to the FTNF002-00 genomic group inside the B.IV clade.

\section{Conclusion}

Here we have presented the draft genome of the first member of FTNF002-00 genomic group of $F$. tularensis subspecies holarctica. As more genetic information of members from this genomic group becomes available, a better understanding of the evolution and biogeography of this pathogen will be gained. This knowledge may help us to understand the epidemiology and potential expansion of the geographical distribution of this genomic group. Despite potential biases associated with discontinuous draft genomes, we would like to

\section{Acknowledgements}

This work was supported by the Dutch Ministry of Defence [grant number V1036] and the Swedish Defence Research Agency [project A4952].

\section{References}

1. Sjostedt A. Family XVII. Francisellaceae, genus I. Francisella. In: Brenner D, Krieg N, Staley J, Garrity G, Boone D, Vos P, et al., editors. Bergey's Manual of Systematic Bacteriology. New York: Springer US; 2005. p. 200-210.

2. Rotz LD, Khan AS, Lillibridge SR, Ostroff SM, Hughes JM. Public health assessment of potential biological terrorism agents. Emerg Infect Dis 2002; 8:225-230. PubMed http://dx.doi.org/10.3201/eid0802.010164

3. Forsman M, Sandström G, Sjöstedt A. Analysis of $16 \mathrm{~S}$ ribosomal DNA sequences of Francisella strains and utilization for determination of the phy- focus on the added value of draft bacterial genome sequencing. Taking advantage of low cost and high-throughput sequencing platforms allows us to probe the vast microbial diversity present in nature and rapidly respond to clinical outbreaks and acute biosecurity hazards. From an evolutionary ecology perspective, increased sequencing efforts allow us to characterize the biogeography of microbial taxa and differentiate between neutral and conserved genome contents. logeny of the genus and for identification of strains by PCR. Int J Syst Bacteriol 1994; 44:38-46. PubMed http://dx.doi.org/10.1099/00207713-44-1-38

4. Brevik OJ, Ottem KF, Kamaishi T, Watanabe K, Nylund A. Francisella halioticida sp. nov., a pathogen of farmed giant abalone (Haliotis gigantea) in Japan. J Appl Microbiol 2011; 111:1044-1056. PubMed http://dx.doi.org/10.1111/j.13652672.2011.05133.x

5. Woese CR, Kandler O, Wheelis ML. Towards a natural system of organisms: proposal for the domains Archaea, Bacteria, and Eucarya. Proc Natl 
Acad Sci USA 1990; 87:4576-4579. PubMed http://dx.doi.org/10.1073/pnas.87.12.4576

6. Garrity GM, Bell JA, Lilburn T. Phylum XIV. Proteobacteria phyl. nov. In: Garrity GM, Brenner D), Krieg NR, Staley JT (eds), Bergey's Manual of Systematic Bacteriology, Second Edition, Volume 2, Part B, Springer, New York, 2005, p. 1.

7. Validation of publication of new names and new combinations previously effectively published outside the IJSEM. List no. 106. Int I Syst Evol Microbiol 2005; 55:2235-2238. http://dx.doi.org/10.1099/ijs.0.64108-0

8. Garrity GM, Bell JA, Lilburn T. Class III. Gammaproteobacteria class. nov. In: Garrity GM, Brenner DJ, Krieg NR, Staley JT (eds), Bergey's Manual of Systematic Bacteriology, Second Edition, Volume 2, Part B, Springer, New York, 2005, p. 1.

9. Garrity GM, Bell JA, Lilburn T. Order V. Thiotrichales ord. nov. In: Garrity GM, Brenner DJ, Krieg NR, Staley JT (eds), Bergey's Manual of Systematic Bacteriology, Second Edition, Volume 2, Part B, Springer, New York, 2005, p. 131.

10. Sjöstedt AB. Family III. Francisellaceae fam. nov. In: Garrity GM, Brenner DJ, Krieg NR, Staley JT (eds), Bergey's Manual of Systematic Bacteriology, Second Edition, Volume 2, Part B, Springer, New York, 2005, p. 199-200.

11. Skerman VBD, McGowan V, Sneath PHA. Approved Lists of Bacterial Names. Int J Syst Bacteriol 1980; 30:225-420.

http://dx.doi.org/10.1099/00207713-30-1-225

12. Dorofe'ev KA. Classification of the causative agent of tularemia. Symposium Research Works Institute Epidemiology and Microbiology Chita 1947; 1:170-180.

13. Owen CR. Genus Francisella Dorofe'ev 1947, 176. In: Buchanan RE, Gibbons NE (eds), Bergey's Manual of Determinative Bacteriology, Eighth Edition, The Williams and Wilkins Co., Baltimore, 1974 , p. 283-285.

14. Huber B, Escudero R, Busse H-J, Seibold E, Scholz HC, Anda P, Kämpfer P, Splettstoesser WD. Description of Francisella hispaniensis sp. nov., isolated from human blood, reclassification of Francisella novicida (Larson et al. 1955) Olsufiev et al. 1959 as Francisella tularensis subsp. novicida comb. nov., and emended description of the genus Francisella. Int J Syst Evol Microbiol 2010;

60:1887-1896. PubMed

http://dx.doi.org/10.1099/ijs.0.015941-0
15. Olsufjev NG, Meshcheryakova IS. Subspecific taxonomy of Francisella tularensis McCoy and Chapin 1912. Int J Syst Bacteriol 1983; 33:872-874. http://dx.doi.org/10.1099/00207713-33-4-872

16. Olsufjev NG, Emelyanova OS, Dunaeva TN. Comparative study of strains of B. tularense in the Old and New World and their taxonomy. J Hyg Epidemiol Microbiol Immunol 1959; 3:138-149. PubMed

17. Sjödin A, Svensson K, Ohrman C, Ahlinder J, Lindgren $\mathrm{P}$, Duodu S, Johansson A, Colquhoun DJ, Larsson P, Forsman M. Genome characterisation of the genus Francisella reveals insight into similar evolutionary paths in pathogens of mammals and fish. BMC Genomics 2012; 13:268. PubMed http://dx.doi.org/10.1186/1471-2164-13-268

18. Wenger JD, Hollis DG, Weaver RE, Baker CN, Brown GR, Brenner DJ, Broome CV. Infection caused by Francisella philomiragia (formerly Yersinia philomiragia). A newly recognized human pathogen. Ann Intern Med 1989; 110:888-892.

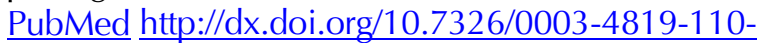
$\underline{11-888}$

19. Larson $\mathrm{CL}$, Wicht W, Jellison WL. A new organism resembling $P$. tularensis isolated from water. Public Health Rep 1955; 70:253-258. PubMed http://dx.doi.org/10.2307/4589039

20. Mörner T, Addison E. Tularemia. In: Williams ES, Barker IK, editors. Infectious diseases of wild animals. 3rd ed. Ames: lowa Stae University; 2001. p. 303-312.

21. Keim P, Johansson A, Wagner DM. Molecular epidemiology, evolution, and ecology of Francisella. Ann N Y Acad Sci 2007; 1105:30-66. PubMed http://dx.doi.org/10.1196/annals.1409.011

22. Liolios K, Chen IM, Mavromatis K, Tavernarakis N, Hugenholtz P, Markowitz VM, Kyrpides NC. The Genomes On Line Database (GOLD) in 2009: status of genomic and metagenomic projects and their associated metadata. Nucleic Acids Res 2010; 38(Database issue):D346-D354. PubMed http://dx.doi.org/10.1093/nar/gkp848

23. Hyatt D, Chen GL, Locascio PF, Land ML, Larimer FW, Hauser LJ. Prodigal: prokaryotic gene recognition and translation initiation site identification. BMC Bioinformatics 2010; 11:119. PubMed http://dx.doi.org/10.1186/1471-2105-11-119

24. Boisvert S, Laviolette F, Corbeil J. Ray: simultaneous assembly of reads from a mix of high-throughput sequencing technologies. Journal of computational biology: a journal of computational molecular cell biology. 2010 Nov;17(11):1519-1533. 
25. Edgar RC. PILER-CR: fast and accurate identification of CRISPR repeats. BMC Bioinformatics 2007; 8:18. PubMed http://dx.doi.org/10.1186/14712105-8-18

26. Lagesen K, Hallin P, Rødland EA, Staerfeldt HH, Rognes T, Ussery DW. RNAmmer: consistent and rapid annotation of ribosomal RNA genes. Nucleic Acids Res 2007; 35:3100-3108. PubMed http://dx.doi.org/10.1093/nar/gkm160

27. Griffiths-Jones S, Moxon S, Marshall M, Khanna A, Eddy SR, Bateman A. Rfam: annotating non-coding RNAs in complete genomes. Nucleic Acids Res 2004; 33(Database issue):D121-D124. PubMed http://dx.doi.org/10.1093/nar/gki081

28. Vogler AJ, Birdsell D, Price LB, Bowers JR, Beckstrom-Sternberg SM, Auerbach RK, Beckstrom-Sternberg JS, Johansson A, Clare A, Buchhagen JL, et al. Phylogeography of Francisella tularensis: global expansion of a highly fit clone. J Bacteriol 2009; 191:2474-2484. PubMed http://dx.doi.org/10.1128/JB.01786-08

29. Svensson K, Granberg M, Karlsson L, Neubauerova $\mathrm{V}$, Forsman $\mathrm{M}$, Johansson A. A real-time PCR array for hierarchical identification of Francisella isolates. PLOS ONE 2009; 4:e8360. PubMed http://dx.doi.org/10.1371/journal.pone.0008360

30. Barabote RD, Xie G, Brettin TS, Hinrichs SH, Fey PD, Jay JJ, Engle JL, Godbole SD, Noronha JM, Scheuermann RH. Complete genome sequence of Francisella tularensis subspecies holarctica FTNF002-00. PLoS ONE 2009; 4:e7041. PubMed http://dx.doi.org/10.1371/journal.pone.0007041

31. Dempsey MP, Dobson M, Zhang C, Zhang M, Lion C, Gutiérrez-Martín CB. Genomic deletion marking an emerging subclone of Francisella tularensis subsp. holarctica in France and the Iberian Peninsula. Appl Environ Microbiol 2007; 73:7465-7470. PubMed http://dx.doi.org/10.1128/AEM.00646-07

32. Pilo $\mathrm{P}$, Johansson A, Frey J. Identification of Francisella tularensis cluster in central and western Europe. Emerg Infect Dis 2009; 15:2049-2051. PubMed http://dx.doi.org/10.3201/eid1512.080805

33. Gyuranecz M, Birdsell DN, Splettstoesser W, Seibold E, Beckstrom-Sternberg SM, Makrai L, Fodor L, Fabbi M, Vicari N, Johansson A, et al. Phylogeography of Francisella tularensis subsp. holarctica, Europe. Emerg Infect Dis 2012; 18:290293. PubMed http://dx.doi.org/10.3201/eid1802.111305
34. Vogler AJ, Birdsell DN, Lee J, Vaissaire J, Doujet CL, Lapalus M, Wagner DM, Keim P. Phylogeography of Francisella tularensis ssp. holarctica in France. Lett Appl Microbiol 2011; 52:177-180. PubMed http://dx.doi.org/10.1111/j.1472765X.2010.02977.x

35. Gehringer H, Schacht E, Maylaender N, Zeman E, Kaysser P, Oehme R, et al. Presence of an emerging subclone of Francisella tularensis holarctica in Ixodes ricinus ticks from south-western Germany. Ticks and tick-borne diseases. 2013 Feb;4(1-2):93100.

36. Svensson K, Sjödin A, Byström M, Granberg M, Brittnacher MJ, Rohmer L, Jacobs MA, Sims-Day EH, Levy R, Zhou Y, et al. Genome sequence of Francisella tularensis subspecies holarctica strain FSC200, isolated from a child with tularemia. J Bacteriol 2012; 194:6965-6966. PubMed http://dx.doi.org/10.1128//B.01040-12

37. Petrosino JF, Xiang Q, Karpathy SE, Jiang $\mathrm{H}$, Yerrapragada S, Liu Y, Gioia J, Hemphill L, Gonzalez A, Raghavan TM, et al. Chromosome rearrangement and diversification of Francisella tularensis revealed by the type B (OSU18) genome sequence. / Bacteriol 2006; 188:6977-6985. PubMed http://dx.doi.org/10.1128//B.00506-06

38. La Scola B, Elkarkouri K, Li W, Wahab T, Fournous G, Rolain JM, Biswas S, Drancourt M, Robert C, Audic $S$, et al. Rapid comparative genomic analysis for clinical microbiology: the Francisella tularensis paradigm. Genome Res 2008; 18:742-750. PubMed http://dx.doi.org/10.1101/gr.071266.107

39. Chanturia G, Birdsell DN, Kekelidze M, Zhgenti E, Babuadze G, Tsertsvadze N, Tsanava S, Imnadze $\mathrm{P}$, Beckstrom-Sternberg SM, Beckstrom-Sternberg JS. Phylogeography of Francisella tularensis subspecies holarctica from the country of Georgia. BMC Microbiol 2011; 11:139. PubMed http://dx.doi.org/10.1186/1471-2180-11-139

40. Karlsson E, Svensson K, Lindgren P, Byström M, Sjödin A, Forsman M, Johansson A. The phylogeographic pattern of Francisella tularensis in Sweden indicates a Scandinavian origin of Eurosiberian tularaemia. Environ Microbiol 2013; 15:634-645. PubMed http://dx.doi.org/10.1111/1462-2920.12052

41. Antwerpen MH, Schacht E, Kaysser P, Splettstoesser WD. Complete Genome Sequence of a Francisella tularensis subsp. holarctica Strain from Germany Causing Lethal Infection in Common Marmosets. Genome announcements. 2013 Jan;1(1). 